\title{
ГЕНЕТИКА И ГЕНОМНАЯ МЕДИЦИНА В ИССЛЕДОВАТЕЛЬСКИХ ПЕРСПЕКТИВАХ СОЦИАЛЬНЫХ НАУК
}

В обзоре публикаций рассматриваются дискуссии ученых о том, к каким социальным изменениям приводит применение генетических технологий, и как результаты генетических исследований влияют на язык социальных наук. Во-первых, развитие генетических технологий и их имплементация в медицинской практике ставят новые этические и юридические вопросы. Например, несмотря на то что некоторые врачи-генетики выступают за проведение клинических испытаний по редактированию генома эмбриона человека, эти эксперименты ограничены этическими требованиями и правовыми нормами. Попытки обойти эти нормы, несмотря на то что таким образом специалист-генетик может помочь пациенту избавиться от заболевания, приводят к резонансным судебным разбирательствам. Иными словами, мы наблюдаем несоответствие между развитием генетических технологий и коллективными представлениями о пределах вмешательства генетики в жизни людей. Во-вторых, генетические исследования претендуют на изменение понимания тела человека, здоровья, идентичности, биографии и формулируют запрос на реконцептуализацию устоявшихся понятий социальных наук, таких как родство, раса, этническая группа. Взаимная рецепция идей биологии и социальных наук и критика в адрес биологического редукционизма, объясняющего социальный мир через биологические процессы, привели к возникновению эпигенетики-направления, изучающего влияние факторов внешней среды на генетические механизмы и претендующего на переосмысление дихотомий биологическое-социальное, природа-воспитание. Эпигенетика представила социальным исследователям новый взгляд на генетические данные и обратила внимание биологов на роль социальных факторов. Эпигенетические исследования меняют аргументацию социальной политики, устанавливая особый «энвайроментальный» фокус в объяснении проблем в сферах здравоохранения и деторождения и меняя подход к определению ответственности, справедливости, социальной дискриминации и неравенства. Возрастающая доступность генетической информации меняет восприятие идентичности: человек рассматривает себя не как автономную единицу, а как носителя определенных генетических характеристик, связывающих его с семьей, этнической группой и людьми со схожими генетическими предрасположенностями. Социальные институты и практики, возникающие в результате проникно-

Александр Юрьевич Долгов - к.социол.н., ст.н.с., отдел социологии и социальной психологии, Институт научной информации по общественным наукам (ИНИОН) РАН; ст. преподаватель, кафедра общей социологии, Национальный исследовательский университет «Высшая школа экономики», Москва, Россия. Электронная почта: adolgov@inion.ru 
вения результатов генетических исследований в повседневную жизнь, становятся предметом изучения для социальных наук.

Ключевые слова: генетика, медицина, эпигенетика, генетизация, социальная политика

DOI: $10.17323 / 727-0634-2021-19-3-533-541$

Изучение генов как элементарных единиц хранения наследственной информации входит в число самых важных достижений современной науки. Постепенно знания о генах из научных лабораторий проникают в повседневную жизнь: развивается сфера геномной медицины, расширяется рынок потребительской генетики, представления людей о генетике становятся частью массовой культуры. Поддержкой этой области исследований активно занимается государство. Так, в рамках федеральной научно-технической программы развития геномных исследований планируется, что в России в ближайшие годы существенно увеличится количество генетических лабораторий (ТАСС 2019). Президент России, выступая на совещании, посвященном реализации упомянутой программы, отметил, что она концентрируется не просто на разработке передовых медицинских технологий, но на жизни, здоровье и безопасности людей (Kremlin.ru 2020). Таким образом, обращение к возможностям генетики востребовано и в политическом дискурсе.

Как и внедрение любых новых технологий развитие генетики вызывает множество этических, правовых и социальных вопросов, создающих отдельное поле для изучения. Генетические исследования меняют понимание человеческого тела, здоровья, идентичности, биографии и предлагают новые теоретические оптики изучения социальной реальности. В России социальных исследований в этой области еще не так много, хотя потребность в них, безусловно, есть. Множество работ о генетике связано с биоэтикой- междисциплинарным направлением, в рамках которого изучаются этические проблемы, возникающие из-за развития биомедицинских технологий. Например, международная дискуссия вокруг заявления российского биолога Д.В. Ребрикова о готовности начать клинические испытания редактирования эмбриона человека (Cohen 2019) стала поводом для публикации коллективного письма российских исследователей-генетиков и специалистов в области биоэтики, в котором подобные эксперименты названы преждевременными и требующими предварительной этической экспертизы (Grebenshchikova 2019). Кроме вопросов биоэтики в работах российских исследователей нашли отражение проблемы неопределенности, эпистемной и коммуникативной асимметрий во взаимодействии врача-генетика и пациента (Широков 2019; Шевченко, Шестак 2019).

В зарубежной научной литературе обсуждаются различные проблемы, связывающие открытия в генетике с их применением в повседневной 
жизни. В первую очередь это касается медицинской сферы. Сахра Гиббон и ее коллеги в вводной статье к специальному номеру журнала Anthropology $\&$ Medicine, посвященному взаимосвязи между геномными исследованиями и генетической медициной, с одной стороны, и «глобальным здоровьем»с другой, выделяют следующие основные проблемы в этом поле (Gibbon et al. 2018): неравенство и социальная справедливость (неравномерность доступа социальных групп к возможностям геномной медицины); генетическая космология (генетические дискурсы меняют понимание индивидуальной и социальной идентичности, создают новый язык описания онтологических вопросов); границы популяционных отличий (с одной стороны, перед медициной стоит задача создания генетически специфических средств лечения для определенных групп населения, с другойопределение различий между группами основано на устоявшихся социальных и биополитических категориях расы, пола, этнической принадлежности). По мнению Ребекки Олсон и Петы Кук, генетическое тестирование стало вызовом для концептуализации дискретного, уникального и автономного Я, понимание которого сложилось в эпоху Просвещения. В рамках геномной идентичности человек рассматривается как носитель общего генетического кода, акцент делается на единой молекулярной материальности, воспроизводящейся через семьи, этнические и диагностические категории (Olson, Cook 2018: 8).

Современные работы по молекулярной биологии не ограничиваются изучением генов как таковых и учитывают более широкий круг параметров, влияющих на наследственность и изменчивость. Поэтому нынешний этап исследований в этой области получил название постгеномики или постгеномной эры. Например, протеомика (направление молекулярной биологии, изучающее белки) обладает большим потенциалом практического использования в персонализированной медицине, чем генетика/геномика. Этот вывод сделан по результатам 35-ти полуструктурированных интервью с учеными-протеомиками (Holmes et al. 2016). С точки зрения разработки диагностических тестов, анализ белков позволяет измерять наличие и тяжесть заболевания, а не только его риск. В протеомике лекарственные средства нацелены не на гены, а на белки в организме, и это расширяет возможности для разработки персонализированных методов лечения. Однако протеомика не смогла предложить нарратив со столь же сильной объяснительной функцией как у генетики и геномики, которые, преобразовывая наше понимание себя, стали частью общественного сознания (Ibid: 59).

Важным направлением современных исследований в молекулярной биологии является эпигенетика, которая ввела в поле анализа фактор окружающей среды и утвердила тем самым неразрывную связь биологического и социального. Эпигенетика исследует молекулярные механизмы регуляции гена, которые преобразуют информацию, полученную из окружающей среды, на генетическом уровне (Meloni 2014: 732). Иными словами, эпигенетика 
способна показать, как генетическая информация изменяется под воздействием социальных и экологических факторов (как социальное преобразуется в биологическое). Эпигенетика стала ответом на односторонние генетизацию и биомедикализацию в изучении человека. Канадские исследователи Шарль Дюпра и др. рассмотрели потенциальные этические, правовые и социальные последствия эпигенетики, проанализировав релевантную научную литературу последних лет (N=118). Они выяснили, что если в первые годы обсуждения эпигенетики преобладал, скорее, нейтральный и оптимистический настрой, то в последние годы наблюдается рост предостерегающих оценок (Dupras et al. 2019:780). В их статье рассмотрен следующий ряд проблем, которые переосмысливаются благодаря эпигенетике.

1. Дихотомия природа-воспитание. Эпигенетика может «примирить» два крайних взгляда на развитие индивидуальности человека: генетический детерминизм и отказ от биологических факторов при объяснении социальных явлений. Вместо того, чтобы концентрироваться исключительно на конкуренции «эгоистичных генов» за «выживание в долгосрочной перспективе» (Ричард Докинз), обновленная теория эволюции, согласующаяся с эпигенетикой, должна включать «экологические» описания наследственности. Геном в этом случае понимается как биосоциальный, а ген, определяемый ранее как стабильная, устойчивая единица, должен быть реконцептуализирован как более пластичный и реагирующий на изменения в различных окружающих средах. Отмечается, что эпигенетика не избавляет от новых форм детерминизма, порождая, например, «энвайроментальный» или «эпигенетический» детерминизм (Ibid: 792-793).

2. «Биологизация» социального. Работы, объединенные этой тематикой, фокусируются на эпистемологическом повороте, который связан с новым пониманием социального в его взаимосвязи с биологическим. В логике эпигенетических процессов экологические и социокультурные условия могут быть поняты как внешние «сигналы», которые «механистически» интернализируются в организме, вызывая долгосрочные биохимические изменения и становясь неотъемлемой частью «эпигенетической истории» человека. Такой взгляд на зависимость «молекулярной» биографии от окружающей среды может быть использован при обсуждении фактов ущемления индивидов и групп в прошлом благодаря обнаружению эпигенетических маркеров на молекулярном уровне. Негативным последствием такого подхода может стать редукция сложных социальных проблем к молекулярным кодам (Ibid: 793).

3. Общественное здравоохранение и социальная политика. По мнению исследователей, благодаря лучшему пониманию здоровья и болезней эпигенетическое объяснение может стать действенным аргументом для совершенствования экологической и социальной политики. Например, эпигенетика может продемонстрировать, как опыт раннего периода жизни влияет на экспрессию генов в более позднем возрасте, позволяя разработать 
социально-политические программы, направленные на улучшение здоровья детей (Dupras et al. 2019: 794-795).

4. Деторождение, воспитание детей и семья. Эпигенетика переключает фокус внимания с индивидуальных действий женщин в репродуктивный период на жизнь будущих матерей до рождения ребенка. Соответственно социальная политика должна быть направлена на улучшение социальных и экономических условий жизни будущих матерей, поскольку это влияет на здоровье следующих поколений (Ibid: 796).

5. Политическая теория (в частности концептуальный анализ теорий ответственности и справедливости). С помощью эпигенетики можно объяснить биологический уровень неравенства между людьми или даже между поколениями. В этом случае в фокус внимания попадает наследственное неравенство, которое несправедливо сокращает жизненные возможности уже при рождении (Ibid: 797).

6. Судебные разбирательства (например, последствия для уголовного права). Вопрос причинности является одним из сложнейших аспектов при доказательстве вины в судебных разбирательствах. Если эпигенетика сможет реконцептуализировать связь между поведенческими расстройствами и прошлым неблагоприятным опытом, то это может повлиять как на прогнозирование совершения криминального деяния, так и на способы наказания, предотвращения и/или исправления такого поведения (Ibid: 798).

7. Проблемы стигматизации и дискриминации. Некоторые исследователи отмечают, что эпигенетический подход может помочь лучше понять биологические инструменты, с помощью которых на протяжении нескольких поколений воспроизводятся несправедливые социальные структуры и дискриминация в отношении отдельных индивидов и социальных групп (Ibid: 799).

8. Защита конфиденциальности. Некоторые ученые обеспокоены защитой конфиденциальности информации участников эпигенетических исследований. Опасность связана с тем, что эта информация может привести к стигматизации и дискриминации индивидов или групп (Ibid: 800).

9. Трансляция знаний (включая анализ дискурса). Эпигенетика связана с высокой научной неопределенностью и сложностью перевода научных результатов в область здравоохранения. Опасения исследователей связаны с использованием риторической силы эпигенетики в идеологических, политических или коммерческих целях (Ibid: 801).

Несмотря на опасения и риски эпигенетика открывает множество возможностей для медицины. По мнению Луки Кьяпперино и Джузеппе Теста, эпигенетика позволяет оптимизировать точность терапевтических стратегий через особенности (как социальные, так и биологические) каждого человека. Вдобавок, эпигенетика, создавая дискурсы молекулярной биографии, становится языком воображения для социальной политики в области медицины и здравоохранения (Chiapperino, Testa 2016). 
В последние годы растет рынок генетического тестирования. Интернет расширил возможности заказа и оплаты тестов, исключив прямой контакт клиента со специалистом, создав возможности для «опубличивания» своей генетической информации (например, создаются генетические социальные сети, в которых люди могут находить друг друга на основе схожих генетических предрасположенностей или вероятности дальнего родства). Исследователь Хэллам Стивенс из Сингапура рассматривает, как люди конструируют свои родословные благодаря генетическому тестированию, и как в этом процессе биотехнологии объединяются с новыми медиатехнологиями, такими как блоги и социальные сети (Stevens 2015). Он отмечает, что изучение истории ДНК влечет за собой специфическое понятие темпоральности, особые стандарты доказательств и иное восприятие идентичности. По его мнению, история ДНК связывает индивидуальную историю (генеалогию) с великими историческими миграциями человека, и поэтому она предоставляет новые способы формирования групповой идентичности, разрушая традиционные нарративы, сфокусированые на нации, этнической принадлежности, культуре и языке (Ibid: 391).

Таким образом, отвечая на вызовы генетизации, социальные науки реконцептуализируют понятия собственного словаря и ограничивают биологический редукционизм в изучении социальных вопросов. В вопросах взаимодействия генетики и социальной политики социальные науки выполняют не только экспертную, но и посредническую функцию, осуществляя трансфер между медицинским дискурсом и дискурсом коллективных представлений о возможностях генетических исследований.

\section{Выражение признательности}

Обзор подготовлен при финансовой поддержке Российского научного фонда (проект № 19-18-00422).

\section{Список источников}

Kremlin.ru (2020) Совещание о развитии генетических технологий в России. Доступно по ссылке: http://kremlin.ru/events/president/news/63350 (дата обращения: 1 июня 2020).

ТАСС (2019) Голикова доложила Путину о планах создать к 2027 году 65 генетических лабораторий. Доступно по ссылке: https://nauka.tass.ru/nauka/7028756 (дата обращения: 25 октября 2019).

Шевченко С. Ю., Шестак А.Г. (2019) Нормативная и дескриптивная неопределенность в геномной медицине. Горизонты гуманитарного знания, (1): 120-130.

Широков А. (2019) «По-русски говорите»: сообщение информации и обратная связь во взаимодействии врача-генетика и пациента. Laboratorium, 11 (2): 125-148. 
Chiapperino L., Testa G. (2016) The Epigenomic Self in Personalized Medicine: Between Responsibility and Empowerment. The Sociological Review Monographs, 64 (1):203-220.

Cohen J. (2019) Embattled Russian Scientist Sharpens Plans to Create Gene-Edited Babies. Science. Available at: https://www.sciencemag.org/news/2019/10/embattled-russianscientist-sharpens-plans-create-gene-edited-babies (accessed 25 October 2019).

Dupras Ch., Saulnier K. M., Joly Y. (2019) Epigenetics, Ethics, Law and Society: A Multidisciplinary Review of Descriptive, Instrumental, Dialectical and Reflexive Analyses. Social Studies of Science, 49 (5): 785-810.

Gibbon S., Kilshaw S., Sleeboom-Faulkner M. (2018) Genomics and Genetic Medicine: Pathways to Global Health? Anthropology \& Medicine, 25 (1): 1-10.

Grebenshchikova E. G. (2019) Russia’s Stance on Human Genome Editing. Nature, 575 (7784): 596.

Holmes Ch., Carlson S. M., McDonald F., Jones M., Graham J. (2016) Exploring the PostGenomic World: Differing Explanatory and Manipulatory Functions of Post-Genomic Sciences. New Genetics and Society, 35 (1): 49-68.

Meloni M. (2014) Biology Without Biologism: Social Theory in a Postgenomic Age. Sociology, 48 (4): 731-746.

Olson R. E., Cook P. S. (2018) Genomics: The Clinical Encounter and Parallels Across Complementary and Personalized Medicine. Sociology Compass, 12 (9): 1-13.

Stevens H. (2015) Genetimes and Lifetimes: DNA, New Media, and History. Memory Studies, 8 (4):390-340. 
Alexander Dolgov

\section{GENETICS AND GENOMIC MEDICINE RESEARCH FROM THE SOCIAL SCIENCES PERSPECTIVES}

This review examines the debate among scholars on what social change is brought about by genetic technologies and how the results of genetic research affect the language of social sciences. Firstly, the development of genetic technologies and their implementation in medical practice raise new ethical and legal challenges. For example, although some geneticists advocate clinical trials to edit the human embryo's genome, these experiments are limited by ethical requirements and legal norms. In other words, there is a discrepancy between the development of genetic technologies and the collective ideas about the limits of genetic intervention in people's lives. Secondly, genetic research claims to change the understanding of the human body, health, identity, biography and formulates a request for the reconstruction of established social science concepts such as kinship, race, or ethnicity. The criticism of biological reductionism, which explains the social world through biological processes, has led to the emergence of epigenetics - a field that studies the influence of environmental factors on genetic mechanisms and claims to rethink the dichotomies of biological-social, nature-nurture. Epigenetic research is changing the reasoning of social policy, establishing a special 'environmental' focus for explaining social issues. The increasing accessibility of genetic information leads to a particular perception of identity because individuals do not view themselves as an autonomous entity, but as bearers of certain genetic characteristics that link them to their families, ethnic groups, and people with similar genetic predispositions. Social institutions and practices resulting from the intromission of genetic research into everyday life are the subject of study for the social sciences.

Keywords: genetics, medicine, epigenetics, geneticization, social policy

DOI: 10.17323/727-0634-2021-19-3-533-541

\section{References}

Chiapperino L., Testa G. (2016) The Epigenomic Self in Personalized Medicine: Between Responsibility and Empowerment. The Sociological Review Monographs, 64 (1): 203-220.

Cohen J. (2019) Embattled Russian Scientist Sharpens Plans to Create Gene-Edited Babies. Science. Available at: https://www.sciencemag.org/news/2019/10/embattled-russianscientist-sharpens-plans-create-gene-edited-babies (accessed 25 October 2019).

Alexander Yu. Dolgov- Cand. Sci. (Sociol.), Senior Research Fellow, Department of Sociology and Social Psychology, Institute of Scientific Information for Social Sciences of the Russian Academy of Sciences (INION RAN); Senior Lecturer, Department of Sociology, National Research University Higher School of Economics, Moscow, Russia. Email: adolgov@inion.ru 
Dupras Ch., Saulnier K. M., Joly Y. (2019) Epigenetics, Ethics, Law and Society: A Multidisciplinary Review of Descriptive, Instrumental, Dialectical and Reflexive Analyses. Social Studies of Science, 49(5): 785-810.

Gibbon S., Kilshaw S., Sleeboom-Faulkner M. (2018) Genomics and Genetic Medicine: Pathways to Global Health? Anthropology \& Medicine, 25 (1): 1-10.

Grebenshchikova E. G. (2019) Russia's Stance on Human Genome Editing. Nature, 575 (7784): 596.

Holmes Ch., Carlson S. M., McDonald F., Jones M., Graham J. (2016) Exploring the PostGenomic World: Differing Explanatory and Manipulatory Functions of Post-Genomic Sciences. New Genetics and Society, 35 (1): 49-68.

Kremlin.ru (2020) Soveshchaniye o razvitii geneticheskikh tekhnologiy v Rossii [Meeting on the Development of Genetic Technologies in Russia]. Available at: http://kremlin. ru/events/president/news/63350 (accessed 1 June 2020).

Meloni M. (2014) Biology Without Biologism: Social Theory in a Postgenomic Age. Sociology, 48 (4): 731-746.

Olson R.E., Cook P. S. (2018) Genomics: The Clinical Encounter and Parallels Across Complementary and Personalized Medicine. Sociology Compass, 12 (9): 1-13.

Shevchenko S. Yu., Shestak A. G. (2019) Normativnaya i deskriptivnaya neopredelennost' v genomnoy meditsine [Normative and Descriptive Uncertainty in Genomic Medicine]. Gorizonty gumanitarnogo znaniya [The Horizons of Humanities Knowledge], (1): 120-130.

Shirokov A. (2019) 'Po-russki govorite': soobshcheniye informatsii i obratnaya svyaz' vo vzaimodeystvii vracha-genetika i patsiyent ['Speak Russian!': Information Delivery and Feedback in Geneticist-Patient interactions]. Laboratorium, 11 (2): 125-148.

Stevens H. (2015) Genetimes and Lifetimes: DNA, New Media, and History. Memory Studies, 8 (4): 390-340.

TASS (2019) Golikova dolozhila Putinu o planakh sozdat' $k 2027$ godu 65 geneticheskikh laboratoriy [Golikova Reported to Putin about Plans to Create 65 Genetic Laboratories by 2027]. Available at: https://nauka.tass.ru/nauka/7028756 (accessed 25 October 2019). 